ISBN 978-93-84468-86-6

2016 International Research Conference on Social Sciences, Humanities and Interdisciplinary Studies

(RCSSHIS-2016)

Pattaya (Thailand) Dec. 16-17, 2016

\title{
Factors of Marketing Mix Influencing Consumer Behavior of Purchasing Vegetables at Parg Klong Talad Market
}

\author{
Dr. WatcharaYeesuntes, and Sirinee Saisanit \\ watchara.yee@kbu.ac.th \\ Sirinee.saisanit@gmail.com \\ Post graduate school of business administration, KasemBunditUniversity,Bangkok
}

\begin{abstract}
The primary purpose of this study was to determine factors of marketing mix influencing consumer behavior of purchasing vegetables at Parg Klong Talad market. The samples were selected from 133 retail merchant who were Parg Klong Talad customers by using a check list and rating scale questionnaire as a tool. Statistical application used for data analysis was percentage, mean, standard deviation, T-test, One-way Anova, and regression analysis.On the basis of the results of this study, it could be concluded that most of respondents considered factors of marketing mix were the most important in medium level. Factors of personal different effected consumer behavior of purchasing vegetables at Parg Klong Talad market at statistical significant 0.05, accepted that factors of personal different, such as gender, age, and monthly income were not effect consumer behavior of purchasing vegetables at Parg Klong Talad market at statistical significant 0.05 and factors of marketing mix correlated to consumer behavior of purchasing vegetables at Parg Klong Talad market at statistical significant 0.05, accepted price was not correlated to consumer behavior of purchasing vegetables at Parg Klong Talad market at statistical significant 0.05 .
\end{abstract}

Keywords: Behavior, factors, and market.

\section{Introduction}

In our daily life, we have seen retail markets, such as neighborhood grocery stores, seven-eleven stores, noodles shops, and flea market, etc. In the meantime, there are some entrepreneurs managing business of wholesalers and sell products to intermediary who sell products to retailers. Wholesalers are important part of business and economy system, because theysell products, services to retailers, and consumer is at the end of line.

Thailand should be the country of interest in agricultural investment to consider because the country has area suited to diverse climates for agricultural productivity, therefore they produce lot of agricultural products and places for distribution, such as Parg Klong Talad market

Which located near Phra Phuttha Yodfa Bridge, Memorial Bridge onMajaraj Street in Bangkok district. In the past, Parg Klong Talad market was an important source of water tradingthen and there after most of canal filledand replaced with streets which change people habit in traveling. Parg Klong Talad market changed from river to street trading instead to make easy accessible to intermediary consumer. Therefore, Parg Klong Talad market is another choice for consume to choose for their conveniences.

As mentioned above, researcher who are vegetables wholesaler has foreseen the importance of business management and services which will bring this study to develop business strategy in order to provide better services to customer. 


\section{The Purpose of the Study}

1. To study the behavior of vegetables buying of middlemen at Parg Klong Talad market.

2. Factors of marketing mix influencing consumer behavior of purchasing vegetables at PargKlongTalad market.

\section{Hypothesis of the study}

1. Personal difference, such as gender, age, occupation, marital status, level of education, monthly income which effect influencing consumer behavior of purchasing vegetables at Parg Klong Talad market.

2. Factors of marketing mix correlate with consumer behavior of purchasing vegetables at PargKlongTalad market.

\section{Research Methodology}

1. The theoretical concepts studied by virtue of consumer behavior and marketing mix (4) consisted of products, prices, distribution channel, and marketing promotion.

2. Population sample were 133 customers who are retailers at Parg Klong Talad market.

3. Duration of the study from January till April 2559.

\section{Benefit of the study}

1. To be aware of the effects that influencing middle man retailer behavior of purchasing vegetables at Parg Klong Talad market.

2. To be aware of factors of marketing mix that influencing middle man retailer behavior of purchasing vegetables at Parg Klong Talad market.

3. Bring data from the study to use as guidelines for service development of vegetables wholesalers in order to meet the requirement of customers.

\section{Conceptual frameworks of the study}

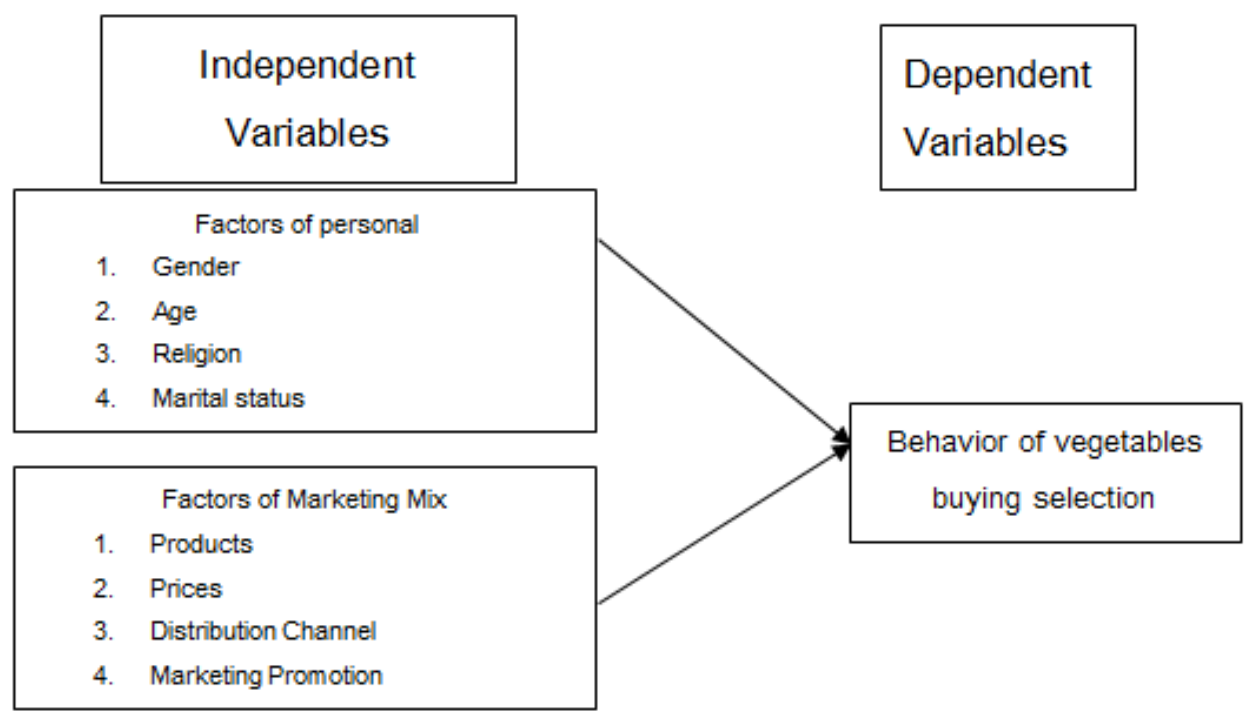

\section{Research Methodology}

\subsection{Sample selection}

The samples were selected from 133 retail merchant who were PargKlongTaladcusto 


\subsection{Data collection procedure}

The questionnaires were distributed to sample of 133vegetables retailers. A total of 133 usable questionnaires were returned back to the researcher, yielding a 100 percent response rate and no missing data.

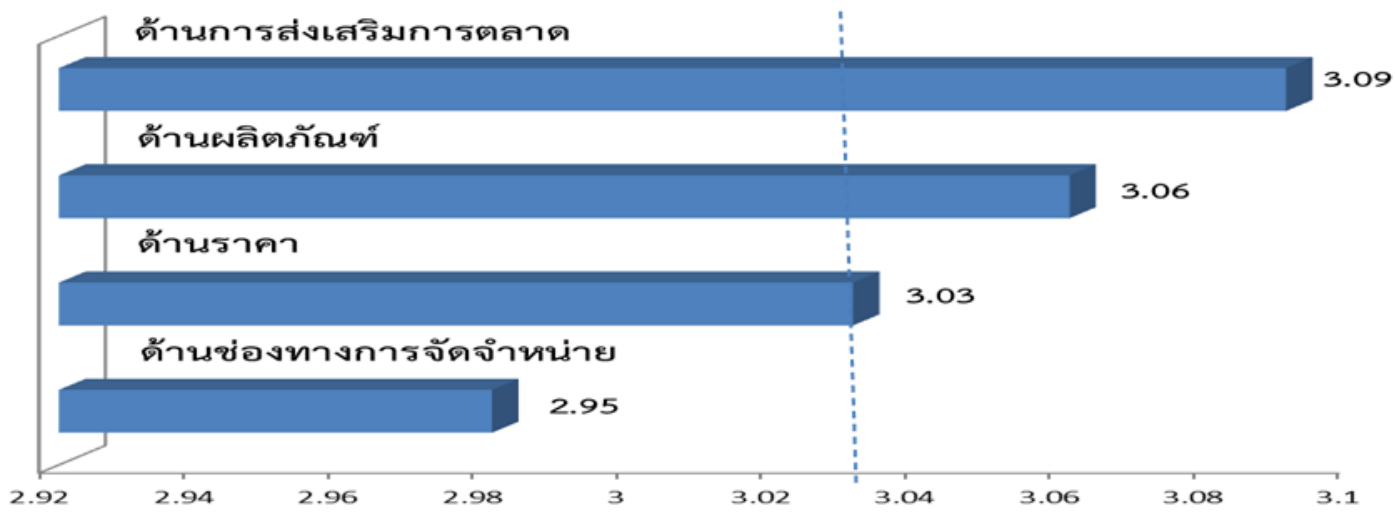

Fig. 1: Results from the study

Figure 1: Shows the average picture of value of marketing mix at $(\bar{x}=3.03)$ which was in medium level when separated into aspects, such as marketing promotion aspect $(\bar{x}=3.09)$ was in medium level, products aspect $(\bar{x}=3.06)$ was in medium level, prices aspect $(\bar{x}=3.03)$ was in medium level, and distribution channel aspect $(\bar{x}=2.95)$ was in medium level.

\section{Marketing mix factors correlated with buying behavior of vegetables at the Parg Klong Talad market.}

TABLE:I Display the hypothesis results of Factors of Marketing Mix Influencing Consumer Behavior of Purchasing Vegetables at Parg Klong Talad Market

\begin{tabular}{|c|c|c|c|c|c|}
\hline \multirow{2}{*}{ Marketing Mix Factors } & \multicolumn{2}{|c|}{$\begin{array}{l}\text { Unstandardized } \\
\text { coefficients }\end{array}$} & \multirow{2}{*}{$\begin{array}{c}\begin{array}{c}\text { Standardize } \\
\text { coefficients }\end{array} \\
\text { Beta }\end{array}$} & \multirow{2}{*}{$\mathrm{t}$} & \multirow{2}{*}{ Sig. } \\
\hline & B & Std. error & & & \\
\hline \multicolumn{6}{|l|}{ products } \\
\hline Standard size of vegetables & .063 & .056 & .115 & 1.122 & .265 \\
\hline Wide range of vegetables & .134 & .054 & .244 & 2.494 & .014 \\
\hline Vegetables with freshness and no disease & .063 & .051 & .121 & 1.230 & .222 \\
\hline Vegetables with quality and last longer & .080 & .053 & .153 & 1.525 & .130 \\
\hline Vegetables available for customer requirement & .135 & .054 & .253 & 2.491 & .014 \\
\hline Season Vegetables & .061 & .067 & .104 & .915 & .363 \\
\hline Controlled vegetable standard & -.030 & .052 & -.056 & -.577 & .566 \\
\hline Inspect vegetables before distribute & .005 & .057 & .009 & .083 & .934 \\
\hline Vegetables with difference grade level & -.046 & .052 & -.088 & -.875 & .384 \\
\hline \multicolumn{6}{|l|}{ Prices } \\
\hline Cheaper price than competitors & .005 & .056 & .009 & .088 & .930 \\
\hline Prices appropriate with vegetable quantity & -.010 & .054 & -.018 & -.184 & .854 \\
\hline Prices appropriate to vegetable quality & -.088 & .053 & -.162 & -1.659 & .100 \\
\hline Prices comparable with competitors & -.035 & .051 & -.068 & -.679 & .499 \\
\hline Adjustable prices with season & -.072 & .051 & -.143 & -1.421 & .159 \\
\hline Prices can be debated & .005 & .054 & .010 & .101 & .919 \\
\hline Quantity of vegetable effect debating & .018 & .057 & .032 & .324 & .747 \\
\hline \multicolumn{6}{|l|}{ Distribution channel } \\
\hline Easy accessible location & .010 & 058 & .019 & .178 & .859 \\
\hline
\end{tabular}




\begin{tabular}{|c|c|c|c|c|c|}
\hline \multirow{2}{*}{ Marketing Mix Factors } & \multicolumn{2}{|c|}{$\begin{array}{l}\text { Unstandardized } \\
\text { coefficients }\end{array}$} & \multirow{2}{*}{$\begin{array}{c}\begin{array}{c}\text { Standardize } \\
\text { coefficients }\end{array} \\
\text { Beta }\end{array}$} & \multirow{2}{*}{$\mathrm{t}$} & \multirow{2}{*}{ Sig. } \\
\hline & B & Std. error & & & \\
\hline Building maintenance with attractive décor & .053 & .052 & .103 & 1.023 & .309 \\
\hline Parking space & .023 & .051 & .044 & .449 & .654 \\
\hline Information center & -.023 & .055 & -.043 & -.419 & .676 \\
\hline Sanitary & -.004 & .054 & -.007 & -.075 & .940 \\
\hline Category of vegetable type & .005 & .052 & .010 & .100 & .921 \\
\hline Transportation services & .086 & .052 & .164 & 1.667 & .099 \\
\hline Assort of Vegetables and available & .107 & .051 & .201 & 2.077 & .040 \\
\hline Vegetable delivery accurately & -.111 & .059 & -.198 & -1.897 & .061 \\
\hline Advertising with all media & .151 & .061 & .249 & 2.460 & .016 \\
\hline \multicolumn{6}{|l|}{ Marketing promotion } \\
\hline Discount prices with repeated customers & .060 & .057 & .100 & 1.051 & .296 \\
\hline Clearly explain about services details & -.074 & .059 & -.132 & -1.265 & .209 \\
\hline Offer information and advice to customer & .099 & .054 & .193 & 1.826 & .071 \\
\hline Discount prices when purchase large quantity & .143 & .053 & .271 & 2.681 & .009 \\
\hline Refund when customers not satisfy & -.036 & .060 & -.061 & -.601 & .549 \\
\hline Fast Delivery and accurately & .130 & .053 & .230 & 2.448 & .016 \\
\hline Service after sale & .039 & .050 & .075 & .779 & .438 \\
\hline
\end{tabular}

\section{Discussion}

On the basis of the results of this study, it could be concluded that factors of marketing mix influencing consumer behavior of purchasing vegetables at PargKlongTalad market with the average picture of opinions were at medium level when considered in each issue revealed that products issue, the overall opinion was at medium level and found that respondents focused onwide range of vegetables which meet customer demand. As for prices aspect, the overall opinion was at medium level and found that respondents focused on appropriate prices with quality of vegetables. As for distribution channel, the overall opinion was at medium level and found that respondents focused on easy access to market. Finally, as for marketing promotion, the overall opinion was at medium level and found that respondents focused on detail of the services.

\section{Recommendation of the study}

Recommendations from the study of factors of marketing mix influencing consumer behavior of purchasing vegetables at PargKlongTalad market were products aspect whichentrepreneur should focus on fresh vegetables without the diseases, clean, and maintain the freshness as long as possible in response to customer demand.Prices aspect whichentrepreneur should focus on adjusting prices according to the seasons.Distribution channel which entrepreneur should focus location with easy access.Finally, marketing promotion which entrepreneur should focus products detail and customer services.

\section{Suggestions to further study}

This study selected samplings group from consumers at PargKlongTalad district only.Therefore, the future study should select samplings group from different demographic area and bring data to compare and get the results to set a new guideline for benefit of all consumers.

\section{References}

[1] PakchanogSrikalla. (2547). Factors of Influencing Consumer Behavior of Purchasing nontoxic fruits in Bangkok, Thesis, Master of Business Administration, Srinakarinviroj University, publisher. 
[2] ArissaraRoongsaeng. (2555). Factors of Influencing Consumer Behavior of Purchasing nontoxic vegetables in Bangkok, Thesis, Master of Business Administration, Srinakarinviroj University, publisher.

[3] VaruneeJeensorn. (2554). Factors of Influencing Consumer on Purchasing nontoxic vegetables in Bangkok,

[4] NattachichaKarunsakul. (2556). Marketing plan for increasing profit of Papaya fruit sale at Jaetee's Papaya. Independent Study, Master of Business Administration, KhonKaen University, publisher. 